\title{
A cross-sectional study of associations between kinesiophobia, pain, disability, and quality of life in patients with chronic low back pain
}

\author{
Josielli Comachio * (1), Mauricio Oliveira Magalhães, Ana Paula de Moura Campos Carvalho e Silva
} and Amélia Pasqual Marques

\begin{abstract}
Background: Low back pain is a significant health problem condition due to high prevalence among the general population. Emotions and physical factors are believed to play a role in chronic low back pain. Kinesiophobia is one of the most extreme forms of fear of pain due to movement or re-injury.

The purpose of this study was to investigate the association between kinesiophobia and pain intensity, disability and quality of life in people with chronic low back pain.

Methods: The study included 132 individuals with chronic back pain, with ages between 18 and 65 years old. Kinesiophobia was assessed using the Tampa Scale of Kinesiophobia, pain intensity was measured using the Numeric Rating Scale with a cut-off more than 3 for inclusion in the study, disability was assessed using the Roland Morris questionnaire, quality of pain was assessed using the McGill questionnaire, and quality of life was assessed using the Quality of Life questionnaire SF-36.

Results: The results are statistically significant, but with weak associations were found between kinesiophobia and pain intensity $(r=0.187$ ), quality of pain (sensory, $r=0.266$; affective, $r=-0.174$; and total $r=0.275$ ), disability $(r=0.399)$ and physical quality of life (emotional $r=-0.414)$.

Conclusion: Kinesiophobia is an important outcome to assess in patients with chronic low back pain. The results suggest that correlations between kinesiophobia and disability and quality of life are statistically significant.
\end{abstract}

Keywords: Kinesiophobia, Low back pain and fear of movement

\section{Background}

Nonspecific low back pain (LBP) refers to pain and discomfort localized in the lumbosacral region, with or without radiating leg pain. The patient often show pain between the costal margins and the inferior gluteal folds, and it is usually accompanied by painful limitation of movement [1]. The prevalence of low back pain in the general population is reported to be up to $18 \%$, increasing to $31 \%$ of the population reporting low back pain in the last 30 days, $38 \%$ in the last 12 months, and $39 \%$ at

\footnotetext{
* Correspondence: josiellicomachio@usp.br

Department of Speech, Physical and Occupational Therapy, School of Medicine, University of Sao Paulo, Cipotânea, n 51, Cidade Universitária, Sao Paulo, Brazil
}

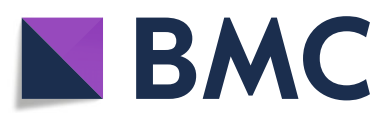

(c) The Author(s). 2018 Open Access This article is distributed under the terms of the Creative Commons Attribution 4.0 International License (http://creativecommons.org/licenses/by/4.0/), which permits unrestricted use, distribution, and reproduction in any medium, provided you give appropriate credit to the original author(s) and the source, provide a link to the Creative Commons license, and indicate if changes were made. The Creative Commons Public Domain Dedication waiver (http://creativecommons.org/publicdomain/zero/1.0/) applies to the data made available in this article, unless otherwise stated.

any point in life [2]. A prognosis of low back pain is directly related to the duration of the symptoms [3-5].

It is estimated that $73.3 \%$ of patients with chronic low back pain suffer from depression [6, 7]. In addition, psychosocial factors (e.g. anxiety, fear, stress, somatization, and socioeconomic problems) have negative impacts on patients with chronic low back pain. One psychological factor that has received much attention in the case of chronic pain is fear in association with disability, related to the intensity and persistence of pain [8]. Kinesiophobia is one of the most extreme forms of fear of pain due to movement or re-injury $[9,10]$.

According to cognitive-behavioral models such as fear-avoidance [11], painful experiences can cause a fear of movement and injury in certain individuals, which 
often leads to behavioral agitation and, in the long-run, depression, and increased levels of functional disability. Furthermore, fear avoidance beliefs and kinesiophobia are relevant factors regarding chronic pain complaints in the general population. Therefore, it is necessary to develop strategies for prevention so that kinesiophobia does not development in patients with low back pain [11]. For low back pain, these prevention initiatives would change in beliefs and attitudes about low back pain [12,13] once the impact on patients' fear of movement about biomechanics to protect the spinal structures has not been well defined [14].

Therefore, the objective of this study was to evaluate kinesiophobia, pain, and functional disability in patients with chronic low back pain and to determine if there are associations of kinesiophobia with any of the measures.

\section{Methods}

This cross-sectional study involved 132 patients with chronic nonspecific low back pain and was approved by the ethics committee of the $x x x x x x x x x x x x x x$ (Protocol XXXXX). We contacted the participants using study flyers, newspaper advertisements, and a list of patients with low back pain at the Specialized Rehabilitation Center. All the participants were confirmed as having chronic nonspecific low back pain, as diagnosed by an orthopedist through a detailed evaluation and imaging ( $x$-ray), to exclude associated diseases. After the evaluation by a physician, the participants were contacted the patients by phone and invited to participate in the study. Participants gave their informed consent before participation. A blind evaluator, a physiotherapist who was trained to evaluate kinesiophobia, pain intensity, functional disability, quality of pain and quality of life, assessed the participants.

The inclusion criteria were: nonspecific chronic low back pain for more than 3 months, an age between 18 and 65 years old, and a minimum pain intensity score of 3 on the Numerical Rating Scale (NRS) [15]. Subjects who had any history of malignancy or spinal fracture, had undergone any surgical procedure in the previous 6 months, had orthopedic or neurological diseases affecting ambulation, or did not understand written and spoken Portuguese were excluded from the study. All the instruments used to assess the outcome measures had previously been translated and adapted to Brazilian-Portuguese versions, and had adequate psychometrical properties [16-20].

Kinesiophobia was assessed using the Tampa Scale of Kinesiophobia, which it was developed to measure the fear of movement due to chronic low back pain. It is a self-report questionnaire of 17 items, and it was used to assess the kinesiophobia of the subjects. Each question has four response options (strongly disagree, disagree, agree, or strongly agree) with scores ranging from 1 to 4 points, respectively. The total score is calculated after inversion of the individual scores of items $4,8,12$, and
16. The total score ranges between 17 and 68 . Increased scores reflect an increased fear of movement [18]. Vlaeyen et al. defined a cut off score of 37 as a high degree of kinesiophobia [21].

Pain intensity was assessed using the numeric pain rating scale (NPRS). This is an 11-point numeric pain scale, ranging from 0 to 10 , on which 0 indicates "no pain" and 10 the "worst possible pain" at the time of the assessment [22].

Quality of pain was assessed using the McGill Pain Questionnaire, a multidimensional assessment of pain. It consists of 77 descriptors of the quantity and quality of pain, grouped into four major domains: sensory, affective, evaluative, and miscellaneous. The domains have 20 sub-domains represented by words that qualify the feelings of pain of a subject, for which intensity values, on a scale of 1 to 5 , are assigned. The questionnaire is used to describe the pain experienced by a subjects and the score is the sum of the aggregate values. Maximum scores for each domain are: sensory $=41$, affective $=14$, evaluative $=5$, and miscellaneous $=17$, with a total possible score of $=77$. The index of the pain assessment of each domain is the sum of the scores of the sub-domains, and each option chosen in domain in questionnaire for represented the pain was the maximum score for each category [17].

Quality of life was assessed using the Short Form Health Survey Questionnaire SF36 to assess health related qualify of life. The Sf36 consists of 36 questions, grouped in eight domains: vitality (4 items), physical functioning (10 items), bodily pain ( 2 items), general health (5 items), physical role limitation ( 2 items), emotional role limitation (3 items), social functioning (2 items), and mental health (5 items). For each section, the score ranges from 0 to 100 , and higher scores reflect better quality of life. In is study, the focus was on the physical and emotional role limitation domains [19].

For disability, the Roland Morris Disability Questionnaire was used to assess functional disability due to low back pain. This questionnaire consists of 24 questions that focus on regular activities in daily living. Each affirmative answer is awarded 1 point and the final score is determined as the total number of points. Total scores range from 0 to 24 , with higher scores reflecting increased disability. Scores above 14 indicate severe impairment [16].

All analyses were conducted using SPSS version 22.0 (IBM Corporation, USA). One-way fixed effects analysis of variance (ANOVA) was used. A statistical power of $80 \%$ (1 $\beta$ error probability) with an $\alpha$ error level probability of 0.05 was chosen to detect between-group differences in the primary outcome measures. A medium effect size of 0.35 was used. Thus, it was estimated the study needed a minimum number of 132 subjects. 
In statistical analysis, mean \pm standard deviation (SD) values were calculated for the quantitative variables and percentages were calculated for qualitative variables. Pearson correlation coefficients and a multiple linear regression model were used to analyze of the associations of the clinical variables (pain intensity, disability, quality of life and pain duration) with kinesiophobia. The following indices were used to rank the correlations: $<0.49=$ low; $0.50-0.69$ = good; $>0.7=$ excellent [23]. Significance was accepted for values of $p \leq 0.05$.

\section{Results}

This study evaluated 132 patients (40 males, 92 females) with chronic low back pain lasting on mean 43 months who reported a mean (SD) of pain and 43.9 (6.6) points of kinesiophobia. Table 1 shows the demographic characteristics the population of is study, and their self-reported levels of kinesiophobia, pain intensity, disability and quality of life.

The Table 2 shows the associations between kinesiophobia and the clinical variables. Kinesiophobia correlated with pain intensity, disability, and physical and emotional roles limitation of quality of life. However, the

Table 1 Demographic and clinical characteristics of the participants

\begin{tabular}{ll}
\hline Variable & Mean (SD) $(n=132)$ \\
\hline Age (years) & $47.4 \pm 9.4$ \\
Weight (kg) & $71.4 \pm 12.8$ \\
Height (cm) & $1.62 \pm 0.9$ \\
BMl (kg/m²) & $27.2 \pm 4.5$ \\
Sex (Male/Female) & $40(30 \%) / 92(69 \%)$ \\
Marital Status & \\
Single & $35(26 \%)$ \\
$\quad$ Married & $79(59 \%)$ \\
$\quad$ Divorced & $13(9 \%)$ \\
$\quad$ Widow & $5(3 \%)$ \\
Use of medication & $96(73 \%)$ \\
Kinesiophobia (17-68) & $43.9 \pm 6.6$ \\
Intensity of pain (0-10) & $7.7 \pm 1.7$ \\
Quality of pain (0-100) & \\
Sensory (0-41) & $20.4 \pm 7.7$ \\
Affective (0-14) & $5.4 \pm 3.4$ \\
Disability (0-24) & $14.0 \pm 5.1$ \\
Quality of life (0-100) & \\
Physical roles limitation & $38.0 \pm 40.6$ \\
Emotional roles limitation & $51.2 \pm 44.4$ \\
Duration of low back pain (months) & $43.8 \pm 32.2$ \\
\hline Categoical varabes ae & \\
\hline
\end{tabular}

Categorical variables are expressed as $\mathrm{n}(\%)$ and the continuous variable are expressed as mean \pm SD. $p \leq 0.05$
Table 2 Correlation between kinesiophobia and the measured clinical variables

\begin{tabular}{|c|c|c|}
\hline & & Kinesiophobia $(n=132)$ \\
\hline & $\mathrm{R}$ & Coefficients $(95 \% \mathrm{Cl})$ \\
\hline Intensity of pain (0-10) & $0.187^{*}$ & $(-0.002$ to 0.364$)$ \\
\hline Quality of pain (0-77) & & \\
\hline Sensory & $0.266^{* *}$ & (0.112 to 0.406$)$ \\
\hline Affective & $0.174^{*}$ & (0.024 to 0.331$)$ \\
\hline Total & $0.275^{* *}$ & (0.117 to 0.433$)$ \\
\hline Disability (0-24) & $0.399^{*}$ & (0.254 to 5.30$)$ \\
\hline Quality of life (0-100) & & \\
\hline Physical roles limitation & 0.111 & $(-0.062$ to 0.276$)$ \\
\hline Emotional roles limitation & $-0.414^{* *}$ & $(-0.560$ to -0.258$)$ \\
\hline Duration of low back pain (months) & 0.105 & $(-0.065$ to 0.258$)$ \\
\hline
\end{tabular}

${ }^{*}$ significant, $p<0.05{ }^{* *}$ significant, $p<0.01$

correlations between kinesiophobia and physical role limitations and the duration of pain were not significant.

Similarly, when the kinesiophobia scores were adjusted for possible confounding variables, (duration of pain, pain intensity, quality of life and disability), no association with the severity of symptoms was observed, except for the emotional role limitation component of quality of life (Table 3).

\section{Discussion}

The objectives of this study were to evaluate kinesiophobia, pain, and functional disability in patients with chronic low back pain and to determine if there were associations of kinesiophobia with the other measured variables. The patients of this study demonstrated weak but statistically significant associations of kinesiophobia with pain intensity, quality of pain, disability and quality of life in the emotional domain. However, there was no association with the duration of symptoms.

The patients of this study scored an average 43.9 points on the scale of kinesiophobia, which is considered a moderate level for patients with chronic nonspecific low back pain [12]. Furthermore, they had other symptoms such as high intensity of pain, low quality of pain and life, frequent use of drugs and another characteristic's. Although the correlations were weak, the results corroborate those of other studies [5, 24-26], supporting the hypothesis that low back pain patients show a worsening prognosis due to the fear of moving, negative thoughts, and sick leave for low back pain.

Some authors [11, 25] have attempted to explain the exact mechanisms and factors related to chronic low back pain, and have reported that a model based on clinical signs and symptoms suggests that intensity and quality of pain are proportional to the extent of tissue injury, which eventually evolves into high levels of 
Table 3 Multiple linear regression model of the comparison between kinesiophobia scores and the clinical variables

\begin{tabular}{lll}
\hline & \multicolumn{2}{l}{ Kinesiophobia $(n=132)$} \\
\cline { 2 - 3 } & Standardized coefficients & Std. Error \\
\hline Intensity of pain (0-10) & 0.249 & 0.326 \\
Quality of pain (0-77) & & \\
$\quad$ Sensory & 0.086 & 0.084 \\
Affective & -0.114 & 0.194 \\
Disability (0-24) & 0.272 & 0.125 \\
Quality of life (0-100) & & \\
$\quad$ Physical roles functional & 0.018 & 0.128 \\
$\quad$ Emotional roles functional & $-0.042^{*}$ & 0.013 \\
Duration of low back pain & 0.003 & 0.008 \\
\hline Significant, $\rho \leq 0.05$ & &
\end{tabular}

Significant, $p \leq 0.05$

disability [27]. However, there is also evidence that the persistence of symptoms of pain cannot be explained by objective clinical findings; therefore, a specific approach based on a biomedical model may prove insufficient due to the complexity of factors that are related to low back pain (e.g. unhelpful beliefs, catastrophizing, maladaptive coping strategies, poor self-efficacy, and depression) [28-30]. It is our opinion that the present study presents weak but confirmatory evidence, that kinesiophobia and low back pain are associated.

According to the biopsychosocial model, some individuals with musculoskeletal pain develop a chronic pain syndrome, the "cognitive model of fear of movement/(re) injury" suggested by Vlaeyen [31], which is based on fear of pain, or more specifically, the fear that physical activity may cause pain and/or recurrence of injury. Two opposing behavioral responses are postulated: 1) individuals choose to face pain in an attempt to improve, believing that the presence of pain does not justify the limitation of their functional activities, or 2) people maintain a fear of movement and believe that the activity is directly related to the presence of pain [32].

According by Sions [27], when beliefs and fear of movement are present in patients with low back pain, kinesiophobia must be considered in the management of patients with LBP. Patients need to be aware that pain may be misinterpreted as being more severe than it is, causing them to be excessively cautious in their actions, thereby causing disability. Our findings regarding kinesiophobia in patients with chronic LBP were significant statistically. The pain intensity and the quality of pain were high in our patients with low back pain and consequently, the emotional quality of life had decreased. The pain intensity and higher levels of kinesiophobia in our low back pain group may also have been associated with low quality of life.
This study was representative of the general population with low back pain in Brazil. A possible limitation of this study was that we did not investigate the relationships between functional outcome tests and kinesiophobia. Moreover, this was a cross-sectional study; therefore, it is not possible to establish causal relationships proving the existence of a temporal sequence between an exposure factor and the subsequent development of the disease. However, cross sectional studies could be carried out as the first step of a cohort study.

\section{Conclusion}

The results of the study of kinesiophobia levels was present, weak to moderate negative correlations existed between kinesiophobia and health-related quality of life at emotional, pain, disability. Even so, it is believed that the results can be useful in the scientific base of professionals Involved in clinical assessment and rehabilitation of people affected by low back pain and kinesiophobia.

Our findings indicate that the kinesiophobia is associated with pain intensity, disability, and quality of life and should be taken into consideration when planning preventive and curative physical therapy programs for patients with low back pain.

\section{Abbreviations \\ LBP: Nonspecific low back pain; NRS: Numerical Rating Scale; SD: Standard deviation; SF36: Short Form Health Survey Questionnaire}

\section{Acknowledgements}

We thank to patients who contributed for do the study and the SER - Center of Rehabilitation, Taboão da Serra, SP.

\section{Authors' contributions}

JC, had the idea of study, wrote, analyzed and interpreted the patient data regarding the low back pain and kinesiophobia. MM, helped analyzed and contributed with the recruited of patients. APMC, statistical analyses. AP, supervised the study. All authors read and approved the final manuscript.

\section{Ethics approval and consent to participate}

This study was approved by the ethics committee of the Ética e Pesquisa da Faculdade de Medicina da Universidade de São Paulo (Protocol 350/13) and all participants gave their informed consent before participation.

\section{Competing interests}

The authors declare that they have no competing interests.

\section{Publisher's Note}

Springer Nature remains neutral with regard to jurisdictional claims in published maps and institutional affiliations.

Received: 7 May 2018 Accepted: 1 June 2018

Published online: 22 June 2018

\footnotetext{
References

1. Airaksinen O, Brox Jl, Cedraschi C, Hildebrandt J, Klaber-Moffett J, Kovacs F, et al. Chapter 4 - European guidelines for the management of chronic nonspecific low back pain. Eur Spine J. 2006;15:192-S300.

2. Nascimento PRC, Costa LOP. Low back pain prevalence in Brazil: a systematic review. Cadernos de Saúde Pública. 2015:31:6.

3. Tulder MW. Chapter I. European guidelines. Eur Spine J. 2006;15:134-5.
} 
4. Costa LDM, Maher CG, McAuley JH, Hancock MJ, Herbert RD, Refshauge KM, et al. Prognosis for patients with chronic low back pain: inception cohort study. Br Med J. 2009;339-82

5. Ulug N, Yakut Y, Alemdaroglu I, Yilmaz O. Comparison of pain, kinesiophobia and quality of life in patients with low back and neck pain. J Phys Ther Sci. 2016;28(2):665-70.

6. Rush A, Polatin P, Gatchel R. Depression and chronic low back pain establishing priorities in treatment. Spine J. 2000;25(20):2566-71.

7. Fanian H, Ghassemi G, Jourkar M, Mallik S, Mousavi M. Psychological profile of Iranian patients with low-back pain. East Mediterr Health J. 2007;13(2): 335-46.

8. Currie S, Wang J. Chronic back pain and major depression in the general Canadian population. Pain. 2004;107(1-2):54-60.

9. Kori S, Miller R, Todd D. Kinesiophobia: a new view of chronic pain behavior Pain Manager. 1990;3:35-43.

10. Pincus T, Vogel S, Burton A, Santos R, Field A. Fear avoidance and prognosis in back pain: a systematic review and synthesis of current evidence. Arthritis Rheum. 2006;54(12):3999-4010.

11. Leeuw M, Goossens MEJB, Linton SJ, Crombez G, Boersma K, Vlaeyen JWS. The fear-avoidance model of musculoskeletal pain: current state of scientific evidence. J Behav Med. 2007:30:77-94.

12. Picavet HS, Vlaeyen JW, Schouten JS. Pain catastrophizing and kinesiophobia: predictors of chronic low back pain. Am J Epidemiol. 2002; 156(11):1028-34

13. George SZ, Calley D, Valencia C, Beneciuk JM. Clinical investigation of painrelated fear and pain catastrophizing for patients with low back pain. Clin J Pain. 2011;27(2):108-15.

14. Atalay A, Arslan S, Dinçer F. Psychosocial function, clinical status, and radiographic findings in a group of chronic low back pain patients. Rheumatol Int. 2001;21(2):65-2.

15. Childs JD, Piva SR, Fritz JM. Responsiveness of the numeric pain rating scale in patients with low back pain. Spine (Phila Pa 1976). 2005;30(11):1331-4.

16. Nusbaum L, Natour J, Ferraz MB, Goldenberg J. Translation, adaptation and validation of the Roland-Morris questionnaire-Brazil Roland-Morris. Braz J Med Biol Res. 2001;34(2):203-10.

17. Costa LDM, Maher CG, McAuley JH, Hancock MJ, Oliveira WD, Azevedo DC, et al. The Brazilian-Portuguese versions of the McGill pain questionnaire were reproducible, valid, and responsive in patients with musculoskeletal pain. J Clin Epidemiol. 2011;64(8):903-12.

18. Souza FS, Marinho CD, Siqueira FB, Maher CG, Costa LOP. Psychometric testing confirms that the Brazilian-Portuguese adaptations, the original versions of the fear-avoidance beliefs questionnaire, and the Tampa scale of Kinesiophobia have similar measurement properties. Spine. 2008;33(9):1028-33.

19. Ciconelli RM, Feraz MB, Santos W. Tradução para a língua portuquesa e validação do questionário genérico de avaliação de qualidade de vida SF36. Rev Bras Reumatol. 1999;39:143-9.

20. Costa LO, Maher CG, Latimer J, Ferreira PH, Ferreira ML, Pozzi GC, et al Clinimetric testing of three self-report outcome measures for low back pain patients in Brazil: which one is the best? Spine. 2008:33(22):2459-63.

21. Vlaeyen JW, Kole-Snijders AM, Boeren RG, van Eek H. Fear of movement/ (re)injury in chronic low back pain and its relation to behavioral performance. Pain. 1995;62(3):363-72.

22. George S, Fritz J, McNeil D. Fear-avoidance beliefs as measured by the fearavoidance beliefs questionnaire: change in fear-avoidance beliefs questionnaire is predictive of change in self-report of disability and pain intensity for patients with acute low back pain. Clin J Pain. 2006;22:197-203.

23. Fleiss JL. The design and analysis of clinical experimental. New York: Wiley Classics Library Edition Published; 1999.

24. Gomes JL, Kingma M, Kamper SJ, Maher CG, Ferreira PH, Marques AP, et al. The association between symptom severity and physical activity participation in people seeking care for acute low back pain. Eur Spine J. 2015;24:452-7.

25. Boersma K, Linton S. Psychological processes underlying the development of a chronic pain problem prospective study of the relationship between profiles of psychological variables in the fear-avoidance model and disability. Clin J Pain. 2006;22(2):160-6.

26. Kasdan AS, Kasdan ML. The RN assistant in hand surgery. Todays OR Nurse. 1987:9(5):28-32.

27. Sions JM, Hicks GE. Fear-avoidance beliefs are associated with disability in older American adults with low back pain. Phys Ther. 2011:91(4):525-34.
28. Sloan TJ, Gupta R, Zhang W, Walsh DA. Beliefs about the causes and consequences of pain in patients with chronic inflammatory or noninflammatory low back pain and in pain-free individuals. Spine (Phila Pa 1976). 2008:33(9):966-72.

29. Darlow B, Fullen BM, Dean S, Hurley DA, Baxter GD, Dowell A. The association between health care professional attitudes and beliefs and the attitudes and beliefs, clinical management, and outcomes of patients with low back pain: a systematic review. Eur J Pain. 2012;16(1):3-17.

30. Shorthouse FM, Roffi V, Tack C. Effectiveness of educational materials to prevent occupational low back pain. Occup Med (Lond). 2016; 66(8); 623-29.

31. Vlaeyen J, Linton S. Fear-avoidance and its consequences in chronic musculosketal pain: a state of the art. Pain. 2000;85:317-32.

32. McKilligin HR. Letter: Women's lib. Can Med Assoc J. 1973;109(7):573-4.

\section{Ready to submit your research? Choose BMC and benefit from:}

- fast, convenient online submission

- thorough peer review by experienced researchers in your field

- rapid publication on acceptance

- support for research data, including large and complex data types

- gold Open Access which fosters wider collaboration and increased citations

- maximum visibility for your research: over $100 \mathrm{M}$ website views per year

At BMC, research is always in progress.

Learn more biomedcentral.com/submissions 